\title{
THE STABILITY
}

\section{OF THE SOLAR SYSTEM}

\section{AND OF SMALL STELLAR SYSTEMS}

Edited by Y. KOZAI

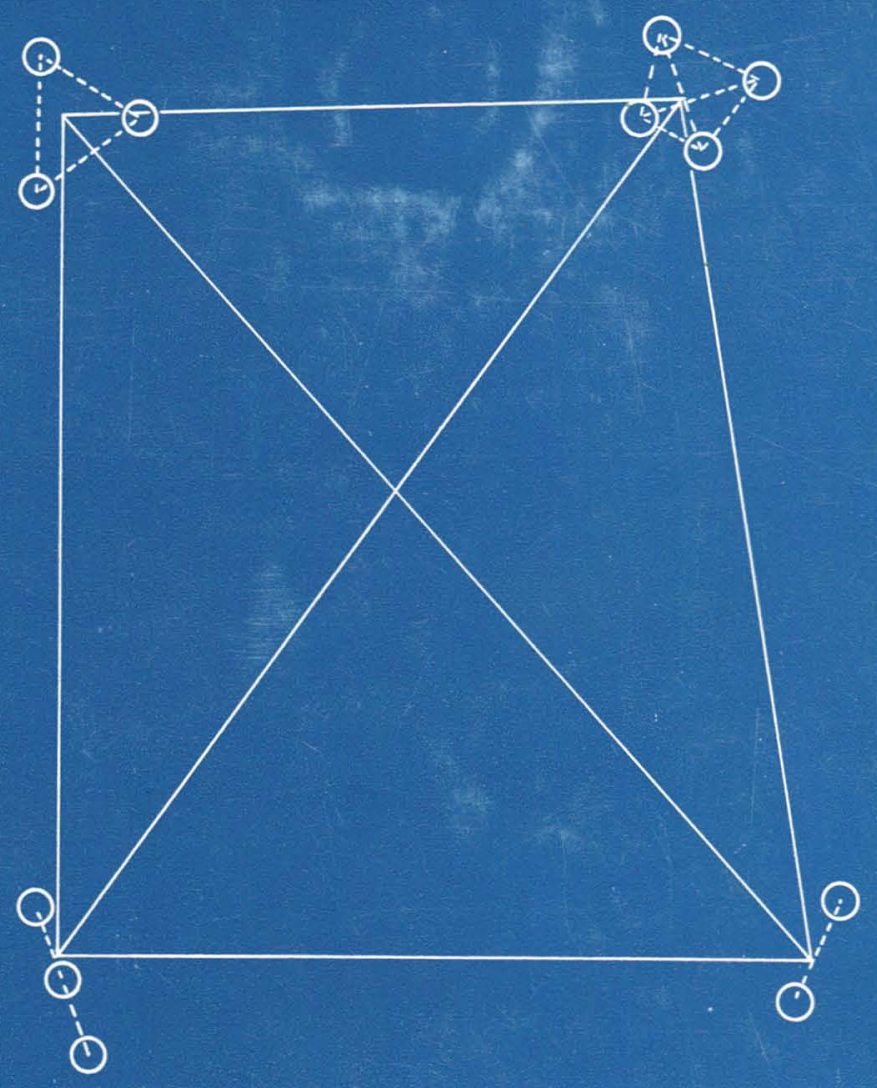


SYMPOSIUM No. 59

STELLAR INSTABILITY

AND EVOLUTION

SYMPOSIUM No. 60

GALACTIC

RADIO ASTRONOMY

SYMPOSIUM No. 61

NEW PROBLEMS IN

ASTROMETRY

SYMPOSIUM No. 63

CONFRONTATION OF

COSMOLOGICAL

THEORIES WITH

OBSERVATIONAL DATA

SYMPOSIUM No. 64

GRAVITATIONAL

RADIATION

AND GRAVITATIONAL

COLLAPSE

SYMPOSIUM No. 65

EXPLORATION OF THE

PLANETARY SYSTEM

SYMPOSIUM No. 66

LATE STAGES OF

STELLAR EVOLUTION

D. REIDEL PUBLISHING COMPANY

DORDRECHT-HOLLAND/BOSTON-U.S.A. 
THE STABILITY OF THE SOLAR SYSTEM AND OF SMALL STELLAR SYSTEMS 
INTERNATIONAL ASTRONOMICAL UNION UNION ASTRONOMIQUE INTERNATIONALE

SYMPOSIUM No. 62

(COPERNICUS SYMPOSIUM I)

HELD AT WARSAW, POLAND, SEPTEMBER 5-8, 1973

\title{
THE STABILITY OF
}

\section{THE SOLAR SYSTEM AND OF SMALL STELLAR SYSTEMS}

\author{
EDITED BY \\ Y. KOZAI
}

Tokyo Astronomical Observatory, Mitaka, Tokyo, Japan

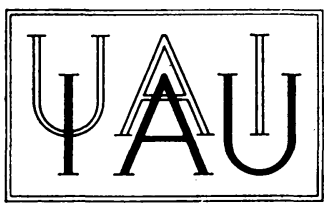

D. REIDEL PUBLISHING COMPANY DOR DRECHT-HOLLAND / BOSTON-U.S.A.

1974 
Published on behalf of

the International Astronomical Union and

the International Union of Theoretical and Applied Mechanics

by

D. Reidel Publishing Company, P.O. Box 17, Dordrecht, Holland

All Rights Reserved

Copyright (C) 1974 by the International Astronomical Union

Sold and distributed in the U.S.A., Canada, and Mexico by D. Reidel Publishing Company, Inc.

306 Dartmouth Street, Boston,

Mass. 02116, U.S.A.

Library of Congress Catalog Card Number 74-76475

Cloth edition: ISBN 9027704589

Paperback edition: ISBN 9027704597

No part of this book may be reproduced in any form, by print, photoprint, microfilm, or any other means, without written permission from the publisher

Printed in The Netherlands by D. Reidel, Dordrecht 


\section{TABLE OF CONTENTS}

J. MOSER / Stability Theory in Celestial Mechanics 1

L. MARK US / Modern Dynamical Systems Theory 11

H. POllard / The Present State of the $n$-Body Problem 19

M. LECAR / Bode's Law 21

H. JEHLE / Distribution of the Mean Motions of Planets and Satellites and the Development of the Solar System 23

J. M. BAR NOTHY / Can the Solar System be Quantized? 25

M. LECAR and F. A. FR A NKLIN / On the Original Distribution of the Asteroids 37

S. F. DER MOT T / The Origin of Commensurabilities in the Satellite Systems 57

S. GASSKA / The Origin of the Asteroid Ring 59

G. A. CHEBOTAREV, N. A. BELYAEV, and R. P. EREMENKO/Orbits of Trojan Asteroids

R. GREENBERG / The Role of Saturn's Oblateness in the Mimas-Tethys Resonance

H. SCHOLL and R. GIFFEN / Stability of Asteroidal Motion in the Hecuba Gap

Y. KOZAI and M. YUASA / Secular Perturbations for Asteroids Belonging to Families

A. BRAHIC / The Formation of Disks by Inelastic Collisions of Gravitating Particles. Applications to the Dynamics of the Saturn's Ring and to the Formation of the Solar System

G. A. K R A SI NS K Y / Stationary Solutions of the Averaged Three-Body Problem and Some Problems of Planet Motion Stability

M. L. LIDOv / Integrable Cases of Satellite Problem with the Third Body and the Oblate Planet

B. GAR FIN KEL / The Global Solution in the Problem of the Critical Inclination

D. BENES T / Retrograde Satellites in the Circular Plane Restricted Three-Body Problem

v. MATAS / A Note on a Separation of Equations of Variation of the Elliptic Restricted Three-Body Problem into Hill's Equations

N. A. BELYAEV and S. D. SHAPOREV/Comet Schwassmann-Wachmann 3 (1930 VI)

L. M. BELOUS / The Motion of Comet Westphal in 1852-1974

N. A. Bokhan and yu. A. Chernetenko / The Motion of Comet EnckeBacklund over 1901-1970 
V. A. BRUMBerg / An Iterative Method of General Planetary Theory

N. I. LOBKova and m. S. Petrovskaya / On the Calculation of Secular Perturbations in the Case of Close Commensurability

P. BRETAGNON / Long Period Terms in the Solar System

S. FERRA Z-MELLo / On the Theory of the Galilean Satellites of Jupiter

J. S. GRIFFITH / Conditions for Escape and Retention

G. I. EROSHKIN/Influence of the Dynamical Figure of the Moon on Its Rotational-Translational Motion

A. H. JU PP / A Comparison of the Mean-Value and Initial-Value Solutions of the Ideal Resonance Problem with an Application in Rigid-Body Mechanics

M. J VALTONEN / Statistics of Three-Body Experiments

D. C. HEGGIE / The Role of Binaries in Cluster Dynamics

L. O. LODÉN and H. RICK MA N / On the Stability of Small Clusters or Cluster Remnants

C. ALLEN and A. POVEDa / The Dynamical Evolution of Trapezium Systems

T. A. AGEKJAN and J. P. A Nosova / The Stability of Triple Stellar Systems

L. Losco / Sur un invariant intégral du problème des $n$ corps: Conséquence de l'homogénéité du potentiel

G. JANIN and M. J. HAGGERTY / Numerical Experiments on Expanding Gravitational Systems

M. HÉNON/ Numerical Experiments on the Stability of Spherical Stellar Systems

R. H. MILLER / On the 'Thermodynamics' of Self-Gravitating $N$-Body Systems

D. G. SA AR I / Dynamics and Clusters of Galaxies

A. S. BARANOV and yu. v. BATRAKOV / Dynamical Friction Effects on the Motion of Stars in Rotating Spherical Clusters

C. FROESCHLÉ and J. P. SCHEIDECKER / On the Disappearance of Isolating Integrals in Dynamical Systems with More than Two Degrees of Freedom 